\title{
CARACTERÍSTICAS FISICOQUÍMICAS Y MICROBIOLÓGICAS DEL AGUA SUPERFICIAL DEL BOSQUE DE CHINCHIQUILLA, NUEVA LIBERTAD, CHIRINOS, CAJAMARCA.
}

\author{
PHYSICOCHEMICAL AND MICROBIOLOGICAL CHARACTERISTICS OF THE SURFACE \\ WATER OF CHINCHIQUILLA FOREST, NUEVA LIBERTAD, CHIRINOS, CAJAMARCA.
}

${ }^{1}$ Lenin Quiñones Huatangari a , Jorge Antonio Delgado Soto ${ }^{\text {b }}{ }^{1}$ Teofanez Adolfo Días Ginez ${ }^{\text {c }}$

\section{RESUMEN}

Se determinó las características fisicoquímicas y microbiológicas del agua del bosque de Chinchiquilla en el sector de Nueva Libertad, Distrito de Chirinos. Para los parámetros físicoquímicos se empleó los métodos de fotocolorimetría, instrumentación, electroquímico y volumetría en los respectivos análisis. Para los parámetros microbiológicos se empleó la técnica del número más probable. Las muestras fueron tomadas de un manantial. Se determinó dieciséis parámetros fisicoquímicos y dos parámetros microbiológicos. Los resultados mostraron que todas las muestras cumplieron con en el valor mínimo permisible para las determinaciones fisicoquímicas, mas no para las determinaciones microbiológicas. Considerando los límites máximos permisibles de calidad de agua para el consumo humano indicado por la Dirección General de Salud (DIGESA). Se clasificó el agua como no apta según el reglamento de calidad del agua para consumo humano, DS N 031-2010-SA. De acuerdo al Decreto Supremo $\mathrm{N}^{\circ}$ 0023-2008-MINAM esta agua es considerada en la sub categoría A1, agua que puede ser potabilizada con desinfección.

Palabras claves: Calidad del agua, parámetros fisicoquímicos, parámetros microbiológicos, coliformes totales y termotolerantes, Nueva Libertad.

\section{ABSTRACT}

The physicochemical and microbiological characteristics of water from Chinchiquilla forest of sector Nueva Libertad, Chirinos were determined. For physicochemical parameters spectrophotometric methods, instrumentation, and electrochemical analysis in the respective volumes were used. For microbiological parameters the most probable number technique was used. Samples were taken from a spring. Sixteen physicochemical and two microbiological parameters were determined. The results showed that all samples met the minimum allowable value for physicochemical determinations, but not for microbiological determinations. Considering the maximum permissible levels of water quality for human consumption by the General Direction of Health (DIGESA), the water was classified as not suitable by the rules of the water quality for human consumption, D.S No. 031-2010-SA. According to Supreme Decree No. 002-2008-MINAM this water is considered in the sub category A1, and can be drinkable with disinfection.

Keywords: water quality, physical and chemical parameters, microbiological parameters, total coliforms and thermotolerant, New Freedom. 


\section{INTRODUCCIÓN}

La calidad del agua se determina comparando las características físicas, químicas y bacteriológicas del agua con protocolos de calidad del agua o estándares. Para ello, se mide la concentración de sus componentes y los efectos o propiedades causadas por la presencia de estas sustancias. Entre los parámetros fisicoquímicos se encuentran los materiales en suspensión, el color, la turbidez, la temperatura, el pH, la conductividad (León, 2006). El riesgo más grave para la salud humana relacionada con la calidad del agua de beber es el derivado de la contaminación microbiológica, particularmente fecal (termotolerante). (Pnuma, 2008; Foster et al., 2003).

El análisis microbiológico es vital en la prevención de epidemias como resultado de la contaminación del agua. El examen no implica la búsqueda directa de los gérmenes patógenos, ya que estos no sobreviven mucho tiempo fuera del cuerpo de los animales y del ser humano de manera que puedan ser detectados en el agua, mientras que los organismos no patógenos que están siempre presentes en el tracto intestinal de los humanos y animales.

Se excretan junto con los patógenos pero en mucho mayor número, ideales para utilizarlos como indicadores de contaminación fecal; los más utilizados son los coliformes, estos son capaces de sobrevivir durante varias semanas bajo condiciones ideales en el medio acuático por lo que pueden ser más fácilmente detectados, y su presencia en el agua es considerada como un índice evidente de la contaminación fecal y por tanto de organismos patógenos (Altherholt et al., 2003).

\section{MATERIALES Y MÉTODOS}

\section{Zona de estudio}

La presente investigación se realizó en un manantial del sector de Nueva Libertad, Distrito de Chirinos, Provincia de San Ignacio y
Departamento de Cajamarca, ver Fig. 1. Se encuentra ubicada en la zona de vida bosque húmedo-Montano Bajo Tropical (bh-MBT) (Sanchez, 2011), forma parte del bosque de neblina de Chinchiquilla (Peña y Pariente, 2015, p. 141). Esta área se encuentra a una altitud de $1800 \mathrm{msnm}$, su flora mayormente está compuesta de Cedro, Romerillo y en su fauna se pueden encontrar halcones, venados, monos y gallitos de las rocas. (Pautrat, 2007, p. 24).

\section{Toma de las muestras}

Para los análisis fisicoquímicos se tomó seis muestras, de una fuente de agua natural (manantial), considerando el promedio de los resultados de cada parámetro obtenido.

La Asociación Americana de Salud Pública (American Public Health Association, APHA), la Asociación Americana de Abastecimiento de Agua (American Water Works Association, AWWA) y la Federación para el control de la Polución de las Aguas (Water Pollution Control Federation, WPCF), han establecido normas internacionales para la caracterización de la calidad del agua (APHA-AWWA-WPCF, 1992) las cuales se encuentran incluidas en los denominados "Métodos Normales para el Exámen de las Aguas y de las Aguas Residuales" (Standard Methods For The Examination of Water and Wastewaster), de común adopción por numerosos países en todo el mundo. En el presente trabajo se ha considerado estas normas para la georeferenciación y toma de muestras.

\section{Determinaciones Fisicoquímicas}

El análisis fisicoquímico se realizó mediante técnicas fotocolorimétricas, volumétricas y electroquímicas respectivamente con los métodos que se indican en la Tabla 1. 


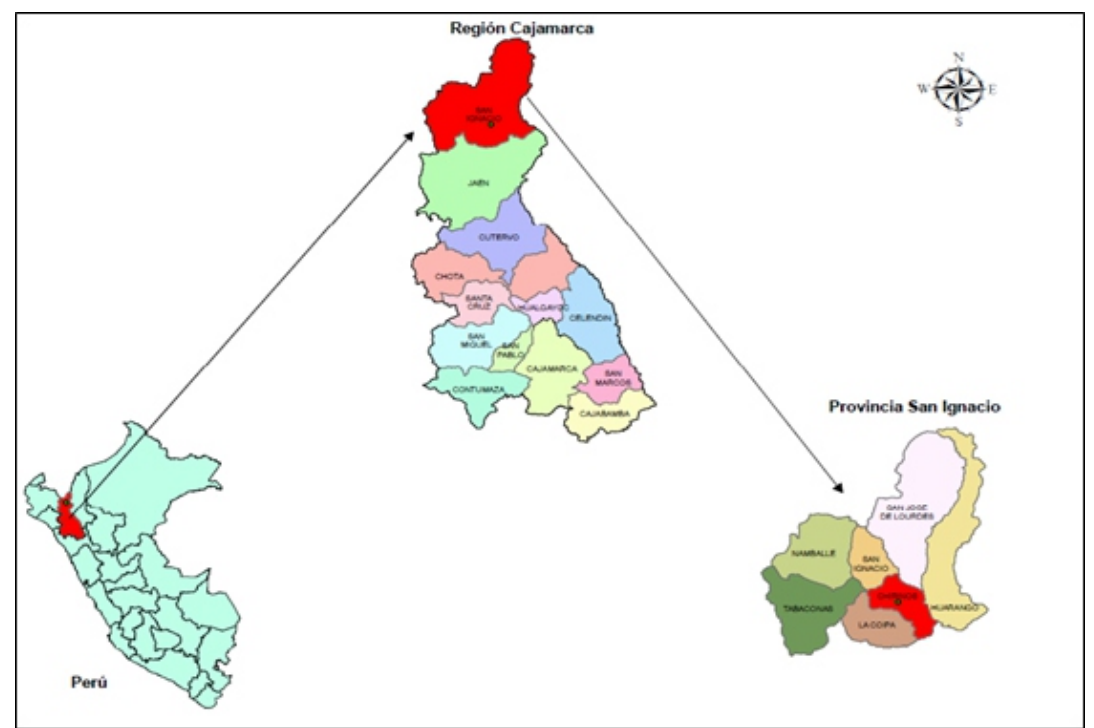

Figura 1. Ubicación de la zona de estudio.

Tabla 1. Técnicas para la determinación de parámetros físico químicos del agua

\begin{tabular}{|c|c|c|}
\hline Parámetro & Metodología & Descripción \\
\hline $\begin{array}{l}\text { Alcalinidad } \\
\text { total }\end{array}$ & Volumetría de neutralización & $\begin{array}{l}\text { Reacción a la fenolftaleina } \\
\text { negativa }\end{array}$ \\
\hline Cloruros & Volumetría de precipitación & $\begin{array}{l}\text { Valoración con nitrato de plata } \\
0.1 \mathrm{~N} \text {, en presencia de indicador } \\
\text { cromato de potasio al } 10 \% \text {. }\end{array}$ \\
\hline Color & $\begin{array}{l}\text { Método estándar Platino - } \\
\text { Cobalto }\end{array}$ & $\begin{array}{l}\text { Lectura en el equipo Colorimetro } \\
\text { DR } 900 \mathrm{HACH}\end{array}$ \\
\hline Cobre & Método 8506 USEPA & $\begin{array}{l}\text { Lectura directa del equipo } \\
\text { Colorimetro DR } 900 \mathrm{HACH}\end{array}$ \\
\hline Conductividad & $\begin{array}{l}\text { Determinación con } \\
\text { Conductivimetro }\end{array}$ & $\begin{array}{l}\text { Lectura directa, previa calibración } \\
\text { del equipo utilizando } \\
\text { Conductímetro marca Hanna, HI- } \\
98129\end{array}$ \\
\hline $\begin{array}{l}\text { Dureza de } \\
\text { Calcio }\end{array}$ & Volumetría complexométrica & $\begin{array}{l}\text { Valoración con EDTA } 0.01 \mathrm{M} \text { en } \\
\text { presencia Buffer pH } 10 \text { y el } \\
\text { indicador NET }\end{array}$ \\
\hline $\begin{array}{l}\text { Dureza de } \\
\text { Total }\end{array}$ & Volumetría complexométrica & $\begin{array}{l}\text { Valoración con EDTA } 0.01 \mathrm{M} \text { en } \\
\text { presencia del indicador murexida- } \\
\text { cloruro sódico e hidróxido de } \\
\text { sodio seis } \mathrm{N} \text {. }\end{array}$ \\
\hline Fierro & $\begin{array}{l}\text { Determinación utilizando equipo } \\
\text { fotocolímetro }\end{array}$ & $\begin{array}{l}\text { Lectura directa del equipo Hach } \\
\text { DR-900 previa incorporación del } \\
\text { reactivo FerroVer (fenantrolina - } \\
\text { p- sal de ácido toluenosulfónico, } \\
\text { hidrosulfito de sodio, metabisulfito } \\
\text { de sodio). }\end{array}$ \\
\hline Manganeso & $\begin{array}{l}\text { Determinación utilizando equipo } \\
\text { fotocolorimetro }\end{array}$ & $\begin{array}{l}\text { Lectura directa del equipo Hach } \\
\text { DR-900 previa incorporación de } 2 \\
\text { reactivos: búfer de tipo citrato de } \\
\text { polvo (acido citrico, sulfato de } \\
\text { sodio, fosfato de sodio y } \\
\text { dibásico), y peryodato de sodio. }\end{array}$ \\
\hline Nitritos & $\begin{array}{l}\text { Determinación utilizando equipo } \\
\text { fotocolorimetro }\end{array}$ & $\begin{array}{l}\text { Lectura directa del equipo Hach } \\
\text { DR-900 previa incorporación del } \\
\text { reactivo NitriVer (ácido } \\
\text { cromotrópico, sal disódico, fosfato } \\
\text { de potasio, pyrosulfato de potasio, } \\
\text { sulfanilato de sodio, monobásico). }\end{array}$ \\
\hline $\begin{array}{l}\text { Oxigeno } \\
\text { Disuelto }\end{array}$ & $\begin{array}{l}\text { Método Winkler. Determinado } \\
\text { en el laboratorio. }\end{array}$ & $\begin{array}{l}\text { Método Normalizado para análisis } \\
\text { de aguas potables y residuales } \\
\text { APHA, AWWA,WPCF } 17 \text { Edición. }\end{array}$ \\
\hline $\mathrm{pH}$ & $\begin{array}{l}\text { Determinación con pHmetro, } \\
\text { realizada en laboratorio }\end{array}$ & $\begin{array}{l}\text { Lectura directa previa calibración } \\
\text { de Equipo con Buffers, utilizando } \\
\text { pHmetro marca Hanna, HI-98129 }\end{array}$ \\
\hline Sulfatos & $\begin{array}{l}\text { Método estándar para la } \\
\text { examinación de agua y aguas } \\
\text { residuales }\end{array}$ & $\begin{array}{l}\text { Lectura directa usando reactivos } \\
\text { SulfaVer en el equipo Hach DR- } \\
900 \text {. }\end{array}$ \\
\hline Temperaturas & $\begin{array}{l}\text { Determinación utilizando equipo } \\
\text { multiparamétrico }\end{array}$ & $\begin{array}{l}\text { Lectura directa en }{ }^{\circ} \mathrm{F} \text { y convertida } \\
\mathrm{a}^{\circ} \mathrm{C} \text {, utilizando el equipo Hanna, } \\
\mathrm{HI}-98129\end{array}$ \\
\hline Turbidez & $\begin{array}{l}\text { Determinación con turbidímetro, } \\
\text { realizada en el laboratorio }\end{array}$ & $\begin{array}{l}\text { Lectura directa, previa calibración } \\
\text { del equipo utilizando turbidimetro } \\
\text { marca Hanna HI } 98703 \text {. Cumple } \\
\text { Norma EPA }\end{array}$ \\
\hline
\end{tabular}




\section{Determinaciones Microbiológicas}

Los parámetros microbiológicos evaluados fueron: Coliformes totales y termotolerantes. En la tabla 2 resumimos las determinaciones realizadas, así como la metodología analítica empleada.

Tabla 2. Determinaciones microbiológicas, técnicas analíticas, medios de cultivo, temperaturas y tiempos de incubación.

\begin{tabular}{lllcc}
\hline \multicolumn{1}{c}{ Ensayo } & Metodología & \multicolumn{1}{c}{ Descripción } & Temperatura & $\begin{array}{c}\text { Tiempo } \\
\text { (h) }\end{array}$ \\
\hline $\begin{array}{l}\text { Coliformes } \\
\text { Totales }\end{array}$ & $\begin{array}{l}\text { Número más } \\
\text { Probable (NMP) }\end{array}$ & $\begin{array}{l}\text { Dilución tubos múltiples, análisis } \\
\text { presuntivo confirmación con Caldo } \\
\text { Lauril sulfato }\end{array}$ & $35^{\circ} \mathrm{C}$ & 48 \\
$\begin{array}{l}\text { Coliformes } \\
\text { Termotolerantes Probable } \\
\text { (NMP) }\end{array}$ & $\begin{array}{l}\text { Resultados de tubos positivos } \\
\text { confirmación con caldo EC. } \\
\text { Verificación con tabla de numero } \\
\text { mas probable }\end{array}$ & $44.5^{\circ} \mathrm{C}$ & 24 \\
\hline
\end{tabular}

\section{RESULTADOS}

\section{Características Fisicoquímicas}

En la Tabla 3 se presentan los parámetros físicoquímicos determinados para el manantial estudiado, además de los límites máximos permisibles dados por el gobierno del Perú para algunos parámetro físicoquímicos encontrados y para los restantes se ha creído conveniente considerar los límites máximos permisibles para aguas superficiales dado por el Center for Innovation in Engineering and Science Education (CIESE). Se observa que el pH fue de 7.42 unidades, este resultado muestra la ausencia de sustancias que puedan afectar el $\mathrm{pH}$ del agua ya que los mismos se mantienen en el rango de la neutralidad.

Tabla 3. Parámetros fisicoquímicos obtenidos de un manantial de Nueva Libertad, Chirinos y límites máximos permitidos por medio de DIGESA(Perú) y el CIESE (2006).

\begin{tabular}{lccc}
\hline Parámetros Fisicoquímicos & $\begin{array}{c}\text { Primavera } \\
\mathbf{2 4 - 0 8 - 2 0 1 5}\end{array}$ & $\begin{array}{c}\text { DIGESA } \\
\text { Perú }\end{array}$ & $\begin{array}{c}\text { CIESE } \\
\mathbf{2 0 0 6}\end{array}$ \\
\hline Alcalinidad total (ppm) & 0.0 & & \\
\hline Cloruro (ppm) & 3.5 & 250 \\
Color (UCV-Pt-Co) & 08.0 & 15 \\
Cobre (ppm) & 0.02 & 2.0 & \\
Conductibidad Eléctrica (mS/cm) & 0.09 & 1500 & \\
Dureza calcio (ppm) & 24.0 & & \\
Dureza total (ppm) & 43.0 & 500 & \\
Fierro (ppm) & 0.02 & 0.30 & $>2,2$ \\
Manganeso (ppm) & 0.02 & 0.4 & \\
Nitritos (ppm) & 0.001 & 0.20 & \\
Oxígeno disuelto (ppm) & 6.55 & $>=6$ & \\
PH & 7.42 & $6.5-8.5$ & \\
Sulfato (ppm) & 0.0 & 250 & \\
Temperatura del aire $\left({ }^{\circ} \mathrm{C}\right)$ & 30.4 & & \\
Temperatura del agua $\left({ }^{\circ} \mathrm{C}\right)$ & 24.1 & & \\
Turbiedad (NTU) & 4.33 & & \\
\hline
\end{tabular}




\section{Características Microbiológicas}

En la tabla 4 se puede observar que los valores para coliformes totales fueron de 17 y además no existieron coliformes termotolerantes.

Tabla 4.Determinaciones de parámetros microbiológicos y limites máximos permitidos usando la técnica del NMP.

\begin{tabular}{lcc}
\hline Parámetro Microbiológico & $\begin{array}{c}\text { Primavera } \\
\mathbf{2 5 - 0 8 - 2 0 1 5}\end{array}$ & $\begin{array}{c}\text { Limites } \\
\text { máximos }\end{array}$ \\
\hline Coliformes Totales, UFC $/ 100 \mathrm{~mL}$ a $35^{\circ} \mathrm{C}$ & 17 & 1.8 \\
Coliformes Termotolerantes, UFC $/ 100 \mathrm{~mL}$ & 0 & 1.8 \\
a $44,5^{\circ} \mathrm{C}$ & & \\
\hline
\end{tabular}

\section{DISCUSIÓN}

Los parámetros fisicoquímicos y microbiológicos son utilizados como indicadores para determinar la calidad del agua en dependencia de su uso, así como para establecer si ha tenido contribución antropogénica (Sardiñas et al., 2006). En nuestro estudio el nivel de oxígeno disuelto fue de $6.55 \mathrm{ppm}$ siendo considerada de buena calidad, tomando como referencia que las concentraciones de oxígeno disuelto por encima de $4.1 \mathrm{ppm}$ es considerada de buena calidad (CIESE, 2006). Las concentraciones bajas en oxígeno disuelto pueden localizarse donde la materia orgánica está en descomposición, lo que significa que las bacterias utilizan el oxígeno para descomponer el desecho, también son bajas en aguas tibias de lento movimiento (Picone et al., 2003). En Uruguay, se realizaron análisis sobre las aguas superficiales y en la cual se reportan concentraciones de nitritos inferiores a $2 \mathrm{ppm}$, además se indica que niveles menores a $3 \mathrm{ppm}$ podrían ser característicos de las aguas naturales (Perdomo et al., 2001). La concentración de nitritos que se obtuvo en el presente trabajo, fue de $0.001 \mathrm{ppm}$ y teniendo como referencia el trabajo anterior se puede corroborar el trabajo de Perdomo. La alcalinidad de la muestra provenientes de la fuente del agua superficial, presentó el valor de 0.0 , esto se debe probablemente a la composición del suelo que se encuentra ubicada en la zona de vida bosque húmedo-Montano Bajo Tropical (bh-MBT), según lo reportado en el mapa ecológico del Perú (INRENA, 1995).

La turbidez del agua está influenciada por los sedimentos y por el plancton existentes en los cuerpos de agua, para aguas superficiales se considera que 0 10 U es una turbidez normal (CIESE, 2006).

El potencial de hidrógeno $(\mathrm{pH})$, es una medida de la concentración de iones hidrógeno. Es una variable muy importante ya que tiene que ver con muchos procesos biológicos y químicos que se dan en los cuerpos de agua. Se reportan valores de 7.42 , el sitio de estudio presentó un nivel óptimo de $\mathrm{pH}$, no rebasando los Criterios Ecológicos de Calidad del Agua (SEDUE, 1989). Con respecto a las determinaciones fisicoquímicas, los niveles cloruro, color, cobre, conductibilidad eléctrica, dureza total, fierro, manganeso, nitritos, sulfato $\mathrm{y}$ turbidez se encuentran dentro de los intervalos citados como normales en la legislación vigente en nuestro país. Esto se puede observar en la Tabla 3. El valor encontrado para coliformes totales nos permite evidenciar que la calidad del agua está afectada. Las bacterias coliformes, se encuentran principalmente en los intestinos de los humanos y de los animales de sangre caliente, y además está ampliamente distribuidas en la naturaleza, especialmente en suelos y vegetales (Gómez, 2005). 
El análisis microbiológico refleja que los valores referenciados en las diferentes normas se cumplen para coliformes termotolerantes; Ministerio de Salud de Perú, 2003; Ministerio da Saude Brasil, 1978).

\section{CONCLUSIONES}

Fisicoquímicamente el agua del bosque de Chinchiquilla, sector de Nueva Libertad, cumple con los límites máximos permisibles para todos los parámetros dados por el reglamento de la calidad del agua para consumo humano en el Perú, DS Nº 031-2010-SA (Ministerio de Salud, 2011) y CIESE 2006.

Bacteriológicamente el agua contiene 17 $\mathrm{NMP} / 100 \mathrm{ml}$ coliformes totales, de esta forma el agua no es apta para el consumo humano de acuerdo con los límites máximos permisibles dados por el reglamento de la calidad del agua en el Perú, DS N 031-2010-SA (Ministerio de Salud, 2011). La presencia de altos niveles de coliformes totales en el agua del manantial es un problema, ya que por el uso al que se destinan, puede ocasionan daños a la salud de los usuarios de Nueva Libertad.

El agua de Nueva Libertad, de acuerdo al Decreto Supremo No 002-2008-MINAM es considerada en la sub categoría A1, agua que puede ser potabilizada con desinfección.

\section{AGRADECIMIENTOS}

A los laboratorios OIKOSLAB.SAC y CADILAB.SAC, de la Provincia de Jaén, Región Cajamarca por sus servicios prestados, para la obtención de los parámetros fisicoquímicos y microbiológicos respectivamente. Agradecemos especialmente a los estudiantes de la Universidad Nacional de Jaén procedentes del Distrito de Chirinos que han colaborado con la toma de las muestras.

\section{REFERENCIAS BIBLIOGRÁFICAS}

Altherholt, T., Feerst, E., Hovendon, B., Kwak, J. y Rosen, J.D. (2003). Evaluation of indicators of fecal contamination in groundwater. Journal American Water Works Association, 95, 119-131.

Foster, S., Hirata, R., Gomes, D., D'Elia, M. y Paris, M. (2003). Protección de la calidad del agua subterránea, guías para empresas de agua, autoridades municipales y agencias ambientales. Ed. Banco Mundial. Washington, D.C. 124 p.

Inrena. (1995). Mapa Ecológico del Perú. Guía Explicativa. 220 p. Lima - Perú

León, V. (2006). Índices de calidad del agua (ICA), formas de estimarlos y aplicación en la cuenca Lerma-Chapala. México: Instituto Mexicano de Tecnología del Agua.

Ministerio de Salud. (2003). Norma sanitaria que establece los criterios microbiológicos de calidad sanitaria e inocuidad para los alimentos y bebidas de consumo humano De los grupos de alimentos y criterios microbiológicos (Vol. 615-2003, p.24).

Ministerio de Salud. (2011). Reglamento de la Calidad del Agua para Consumo Humano DS $\mathrm{N}^{\circ}$ 031-2010-SA. Disponible en http://www. digesa .minsa.gob.pe/publicaciones/descargas/reg lamento_calidad_agua.pdf

Ministerio Da Saúde Brasil. (1978). Resolução CNNPA n $n^{\circ}$ 12, de 1978 Frutas secas ou dessecadas (Vol. 12-1978, p.75). Brasil: Agência Nacional de Vigilância Sanitária.

Pautrat, L. (2007). Propuesta de lineamientos generales para la construcción de un plan de controly vigilancia forestal con participación ciudadana en la provincia de San Ignacio - Cajamarca, p.24. 
Peña, G y Pariente, E. (2015). Composición y diversidad arbórea en un área del bosque Chinchiquilla, San Ignacio - Cajamarca, Perú. Revista Científica Arnaldoa 22 (1): 139-154.

Pnuma. (2008). Water Quality for Ecosystems and Human Health. $2^{\mathrm{a}}$ ed. PNUMA, ERCE, UNESCO.

Sánchez, S. (2011). Zonas de vida de Cajamarca, San Ignacio - Perú. [En línea], San Ignacio - Perú. D i s p o n i b 1 e e $n$ http://zeeot.regioncajamarca.gob.pe/sites/ default/files/ZonasVidas ZEE Según Mapa Nacional .pdf [Consultado el 15 de noviembre del 2015].p. 26

S.E.D.U.E (1989). Secretaria de Desarrollo Urbano y Ecología. Criterios ecológicos de calidad del agua CE-CCA-001/89. Diario oficial de la federación, 2 de diciembre de 1989. Tomo CDXXX. N. ${ }^{\circ}$ 9. México, D.F

Perdomo, C., Casanova, O. y Ciganda, V. (2001). Contaminación de aguas subterráneas con nitratos $y$ coniformes fecales en el litoral sudeste de Uruguay. Agrociencia V(1):10-22.

Picone, L., Andreoli, Y., Costa, J., Aparicio, V., Crespo, L., Nannini, J y Tambasio, w. (2003). Evaluación de nitratos y bacterias coniformes en pozos de la cuenca alt del arroyo pantanoso. RIA 32(1):99-110. Buenos Aires.

Sardiñas, O., Chiroles, S., Fernández, M., Hernández, Y., Pérez, Adisbel. (2006). Evaluación fisico-química y microbiológica del agua de la presa El Cacao (Cotorro, Cuba). Higiene y Sanidad Ambiental 6:202-206.

Gómez, A. (2005). Reconocimiento estacionales de hidrología y plancton en la laguna de Términos.

Méjico (1964/1965). Disponible en http://puma.sskii.gu.se/cubataller
CIESE-Center for Innovation in Engineering and Science Education. (2006). Estudio Internacional Ambiental de la Calidad del Agua. Disponible en http://www.k12science.org/curriculum/dippr oj/es/

APHA-American Public Health Association. (1998). Standard Methods for The Examination of Water and Watewater. 20Th edition.

\section{CORRESPONDENCIA}

Lenin Quiñones Huatangari

Jirón Triunfo $\mathrm{N}^{\circ} 137$ A - Chachapoyas Amazonas - Perú.

biobiolenin@gmail.com

lenin.quinones@umtrm.edu.pe 